\title{
Omnichannel Business
}

\author{
Christiane Lehrer ${ }^{1} \mathbb{D} \cdot$ Manuel Trenz ${ }^{2} \mathbb{D}$
}

Received: 4 December 2020 / Accepted: 28 October 2021 / Published online: 8 January 2022

(c) The Author(s) 2022

\begin{abstract}
The widespread diffusion of digital technologies along with evolving consumer behaviors and requirements have fostered the emergence of omnichannel businesses, i.e., firms that can exploit integrated processes and information systems to realize a seamless and consistent consumer experience across a plenitude of digital and physical channels. To date, omnichannel research has been cluttered and characterized by significant terminological ambiguity that creates unnecessary challenges for researchers and markeeters trying to navigate and advance research and practice in this area. This fundamentals article seeks to address this problem by presenting a definition of omnichannel business that is grounded in its unique characteristics involving technology, organizational, and market perspectives and clearly distinguishes omnichannel from other terms, such as multi-channel or cross-channel. We leverage this conceptual clarity to analyze and structure the previous research on omnichannel business and conclude with an integrated framework that signifies fields of interest for future omnichannel business research.
\end{abstract}

Keywords Omnichannel business · Omnichannel commerce $\cdot$ Multichannel business · E-commerce Channel choice . Cross-channel

JEL classification $\mathrm{O} 330 \cdot \mathrm{M} 100$

\section{Introduction}

Strong growth rates in digital commerce across the world (Lipsman, 2019) and dynamic consumer preferences have motivated the majority of firms to engage in both physical and digital channels (i.e., become multichannel businesses). However, the breadth of channels offered is no longer a differentiator, but is rather a norm (Banerjee, 2014). Equipped with advanced digital devices and services, consumers are empowered to decide on their own how and when to interact with firms, and many combine different digital and

Responsible Editor: Rainer Alt

Manuel Trenz

trenz@uni-goettingen.de

Christiane Lehrer

cl.digi@cbs.dk

1 Department of Digitalization, Copenhagen Business School, Howitzvej 60, 2000 Frederiksberg, Denmark

2 Faculty of Business and Economics, Georg-August-Universität Göttingen, Platz der Göttinger Sieben 5, 37073 Göttingen, Germany physical channels along their customer journey (Hosseini et al., 2018). They move fluently between digital and physical environments, adopt new channels, abandon others, or use them simultaneously (e.g., using a mobile phone in a store). This development has triggered efforts to integrate firms' processes and IT systems across channels to provide a consistent and seamless experience, regardless of which channel consumers prefer in a particular situation or at a particular step of a transaction (Nüesch et al., 2015; von Briel, 2018). As a result of this transformation process, omnichannel businesses are emerging. Omnichannel businesses manage channels in an integrated fashion to leverage synergies between them, enhance the customer experience across channels beyond what is feasible via either channel, and thus maximize the overall performance (Trenz et al., 2020; Verhoef et al., 2015).

In recent years, the concept of the omnichannel business has attracted increasing interest in both research and practice. In practice, both traditional and digital firms have embarked on the journey to become omnichannel businesses and gradually integrate their channel portfolio by offering omnichannel services. For example, the physical store is 
complemented with the mobile channel (Barann et al., 2020; Piotrowicz \& Cuthbertson, 2014), which provides consumers with in-depth product information, location-based push messages with personalized offers, self-scanning services, or home delivery for products that are not available in-store (Grewal et al., 2017). Similarly, digital channels are complemented by services in physical stores, when consumers can check online for product availability at a nearby store and pick up, reserve, or return their online purchases there (Jindal et al., 2021). Traditionally offline-oriented retailers such as IKEA, Nordstrom, and Home Depot as well as onlineoriented retailers such as Amazon, Alibaba, and JD.com are prominent examples of companies that can be considered state-of-the-art omnichannel businesses (Euromonitor International, 2018). However, omnichannel practices evolve quickly, and regular reports summarize their current best practices in different parts of the world (Euromonitor International, 2018; 2021; Forrester, 2020).

Becoming an omnichannel business is seen as one of the most important prospects and goals in firms with promises such as cost savings, increased customer loyalty and satisfaction, and the realization of competitive advantages over pure online retailers (Amar et al., 2020; Väänänen, 2020). At the same time, implementing an omnichannel strategy involves significant technological challenges and a transformation of organizational and operational processes, is associated with considerable costs, and carries a substantial risk of failure if the transformation process is inadequately executed (Matthews, 2013).

For a long time, research has treated channels as separate entities, investigating phenomena such as consumer choices between alternative channels for different stages of the purchase process (e.g., Balasubramanian et al., 2005), differences in willingness to pay between channels (e.g., Wang et al., 2015), or informational spillover effects between separate physical and digital channels (e.g., Pauwels et al., 2011). However, omnichannel business expands well beyond this dichotomous view on multiple channels employed by a single firm (Trenz et al., 2020). Scholars across different disciplines have started to embrace the omnichannel concept resulting in increasing research efforts in this domain (e.g., Bell et al., 2018; Hübner et al., 2016c; Trenz et al., 2020). From an information systems perspective, the prospects and challenges of omnichannel business present exciting opportunities for research that tie in with a multitude of existing research streams such as digital service development and design, blended service experiences, customer-centric design, user behavior, IT governance, interactions between business and IT departments, integration of IT assets, and the management of legacy IT systems to disentangle the complex challenges and opportunities that arise in an omnichannel world.
Despite the unquestioned importance of the omnichannel business concept for research and practice, terminological ambiguity among marketeers and researchers presents significant challenges for anyone trying to grasp the current body of knowledge in this area, orient themselves and ground new research opportunities. The contribution of this fundamentals article is therefore threefold: First, we present a definition of the omnichannel business concept that goes beyond the consumer focus established in marketing studies (Verhoef et al., 2015) by also reflecting the firm. It thus serves as an equally fruitful foundation for researchers investigating the technological, organizational, or market-related aspects of omnichannel business. Second, we identify and structure prior literature that centers on the omnichannel business concept while acknowledging the inconsistent terminology used in those studies. By conducting a scoping review (Pare et al., 2015) that is focused on studies investigating aspects of omnichannel business, we examine the range and nature of this broad research area and summarize prior work. It is our goal to help other researchers orient themselves quickly within this previously cluttered research area. Third, we combine our investigation of the characteristics of omnichannel business and the identified themes from prior studies to identify significant opportunities for future research in the area of omnichannel business. The proposed research framework is intended to both inspire researchers and to help them position their own work.

\section{Definition and characteristics of omnichannel business}

Despite the widespread use of the term omnichannel business, there is no uniformly accepted definition of what constitutes omnichannel business. As discussed in the previous section, implementing an omnichannel strategy has significant implications for the firm's resources and capabilities as well as for consumers' interactions and transactions with the firm. Thus, pinpointing the characteristics of omnichannel business must reflect both the firm as well as the consumer. Focusing on the consumer, Verhoef et al. (2015) define omnichannel business as "the synergetic management of the numerous available channels [...] in such a way that the customer experience across channels and the performance over channels is optimized" (p. 176). This implies that channels, which are typically referred to as either digital (e.g., websites, mobile apps, social media) or physical (e.g., physical stores, agencies) media for interacting with consumers (Hosseini et al., 2018), ${ }^{1}$ are interchangeably and

\footnotetext{
${ }^{1}$ We refer to physical channels when we consider (also digitized) retail stores (e.g., using digital shelves and price tags, virtual reality (VR) and augmented reality (AR) solutions, robots as consultants) to digital channels when considering electronic or mobile communication and transaction channels.
} 
seamlessly used during the customer journey. This journey encompasses the consumer's decision-making process from pre-sales and purchase to post-purchase support. Omnichannel business provides the consumer with a consistent and seamless experience, regardless of the channel used or the phase of the purchase process (Brynjolfsson et al., 2013; Piotrowicz \& Cuthbertson, 2014; Rigby, 2011; Trenz et al., 2020). By implementing an omnichannel strategy, firms aim at increasing customer satisfaction and engaging the consumer on all channels (Beck \& Rygl, 2015), ultimately resulting in increased sales (Hansen \& Sia, 2015).

Although it is the focus of attention and visibility, this consumer viewpoint is not enough to understand what characterizes an omnichannel business. Figure 1 illustrates a typical omnichannel transaction in which the consumer moves between different channels within one transaction, whereby the digital channel can include, for example, e-commerce websites and marketplace platforms as well as various interfaces such as mobile websites, apps, smart products, or voice-based assistants. It becomes apparent that creating this omnichannel experience comes with significant technological and organizational challenges for the firm as it engages with market demands and opportunities. In fact, as of today, most retailers and firms from other industries fall short in the integration of their channels (Verhoef et al., 2015; von Briel, 2018). Omnichannel business demands notable investments in technological infrastructure (Luo et al., 2016) including integrated product information systems, real-time inventory systems, integrated pricing and billing systems, and integrated customer relationship management. As firms entering the omnichannel sphere are typically equipped with the baggage of legacy systems, the transformation of technological infrastructure and organizational structures and capabilities to work seamlessly across multiple channels is both costly and risky (Chen et al., 2018). Despite these challenges, the cross-channel integration can also lead to new possibilities, such as the exploitation of rich consumer data from various channels, which can then be used to create a comprehensive consumer profile (Brynjolfsson et al., 2013; Hansen \& Sia, 2015) or efficiency gains and cost savings. As a result, omnichannel business must consider both the firm as well as the consumer viewpoint.

Building on these considerations, we define an omnichannel business as a firm that can exploit integrated processes and information systems for realizing a seamless and consistent consumer experience across a plenitude of digital and physical channels. As very few firms have achieved this aspired state of being an omnichannel business, we define the term omnichannel strategy as a firm's pursuit of becoming an omnichannel business. Our definition of omnichannel business involves three major perspectives: The first refers to the technology that enables integrated processes and interactions. This perspective is characterized by the tension between technological innovations and legacy solutions. The second refers to the organization that must be able to exploit those strategies, pertaining to questions such as business models, capabilities, and culture. The last one refers to the market, that is, how a seamless and consistent consumer experience should look like. This refers to competitive elements as well as customer roles and requirements.

We characterize omnichannel businesses by contrasting them with multichannel businesses. We distinguish six dimensions of channel integration that pertain to the firm and to the consumer viewpoints. To be considered a fully developed omnichannel business, consumers must be able to make use of seamless and consistent (1) channel transitions and (2) customer experiences (Piotrowicz \& Cuthbertson, 2014; Verhoef et al., 2015), while firms internally must

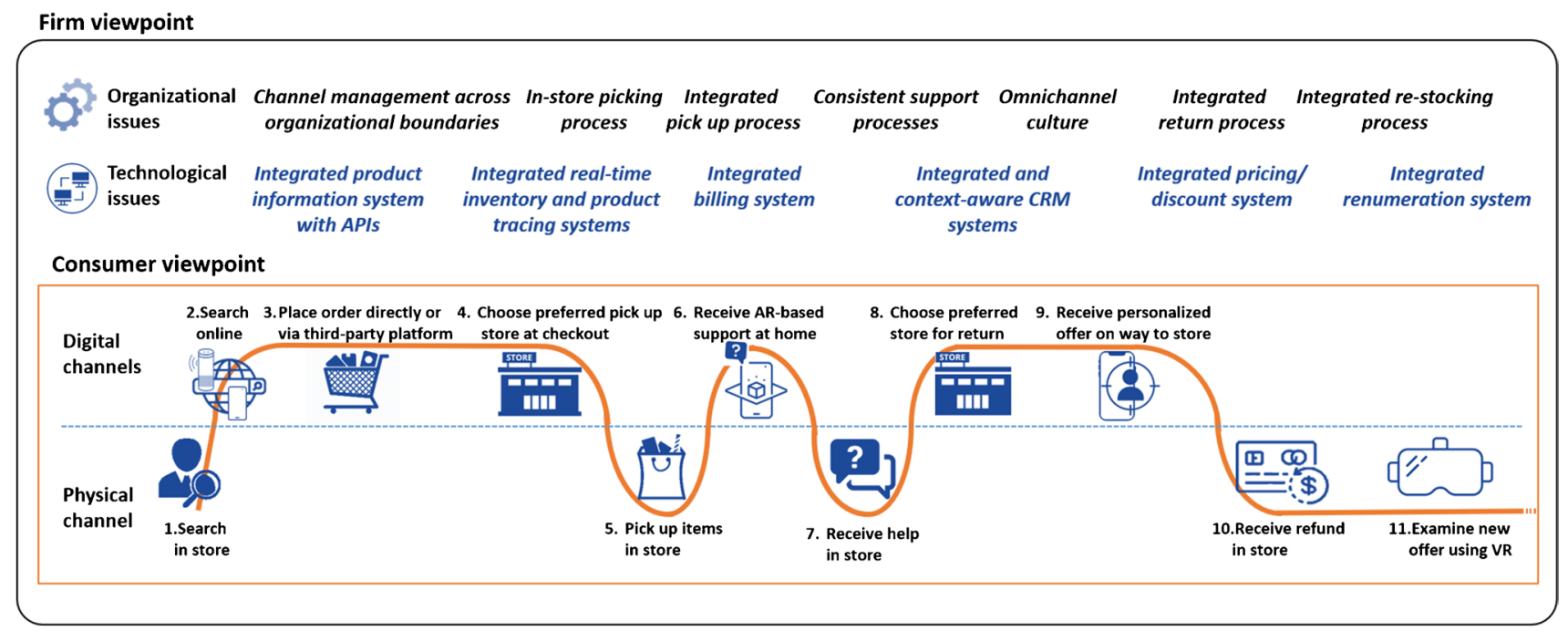

Fig. 1 Example of an omnichannel interaction from a consumer viewpoint and selected related organizational and technological issues from the firm viewpoint 
exploit integrated (3) information systems, (4) channel management, (5) incentive schemes (Mirsch et al., 2016; Shen et al., 2018), and (6) logistics (Hübner et al., 2016a). As a result, they aim to eliminate the barriers between channels by coordinating the processes and technologies across them. Multichannel businesses, on the other hand, are firms that offer consumers two or more channels that are typically treated as independent silos and optimized separately (Beck \& Rygl, 2015; Verhoef et al., 2015). However, the transition from multichannel to omnichannel is a gradual process, and other terms such as cross-channel (i.e., "the possibility for a consumer to switch between certain, but not between all, available channels" (Mirsch et al., 2016, p. 6)) refer to intermediate manifestations on this continuum. ${ }^{2}$ Figure 2 contrasts a multichannel business and a fully developed omnichannel business along the above-mentioned dimensions.

\section{State of research}

Given its practical relevance, omnichannel research has evolved substantially in recent years across multiple domains. To provide an overview of the range and nature of the available literature on this broad research area, we conducted a scoping review (Paré et al., 2015). Scoping reviews seek to map the relevant literature by presenting key themes underpinning a research area as well as the main sources and types of evidence available. This serves as the basis to derive relevant questions and topics for future research. We followed a systematic approach to identify relevant articles across disciplines (see Appendix). When selecting articles, we focused on empirical or prescriptive studies (rather than conceptual papers, e.g., Beck \& Rygl, 2015) and ensured that they are in line with our definition of omnichannel business; that is, they focus on integrated channels rather than treating them as separated entities. The terminological ambiguity made it necessary to extract not only those papers that explicitly use the term, but also those that implicitly relate to the concept of omnichannel business. In line with our definition, we consistently use the term omnichannel business in the following to refer to such research.

Our review revealed that little research has embraced the complexity of omnichannel endeavors in its entirety. Instead, omnichannel research has focused on either firms or consumers. Further clustering the literature, we identified three themes, namely strategy \& transition, management, and impact of omnichannel business, which are summarized in Fig. 3 and discussed in the following.

\footnotetext{
${ }^{2}$ For a detailed discussion of the multi- and crosschannel concepts, see Mirsch et al. (2016) and Yrjölä et al. (2018)
}

\section{Research theme 1: Strategy and transition to omnichannel business}

Prior to transitioning to an omnichannel business, firms must assess their organizational readiness (Berman \& Thelen, 2004) and select an appropriate (omnichannel) strategy (Kim \& Chun, 2018) that meets consumers' channel preferences and is efficient to operate. Hosseini et al. (2018) propose an economic decision model that allows firms to identify the omnichannel strategy (i.e., which channels they should offer along the customer journey) with the highest contribution to long-term firm value.

Transitioning from multichannel toward omnichannel business entails fundamental changes in (1) technology, (2) logistics, and (3) organizational practices (Cao, 2014; Hansen \& Sia, 2015; Wulf et al., 2017). All of those three aspects have sparked significant interest among omnichannel researchers. First, transitioning to omnichannel business demands notable investments in technological infrastructure (Luo et al., 2016) and the development of specific IS capabilities (Hosseini et al., 2017) to process and analyze consumer data across channels (Bradlow et al., 2017; Cao, 2014). Firms need to integrate their information systems (Cao, 2014) such as customer relationship management (CRM), enterprise resource planning (ERP), and billing systems across channels (Wollenburg et al., 2018). They also need to invest in technologies allowing them to acquire consumer knowledge and sense consumers' situational context, for example, via in-store-tracking technologies (Bradlow et al., 2017; Hosseini et al., 2017).

As firms expand and integrate their channel portfolio, the technological infrastructure must support the integration and storage of large amounts of data from various channelsranging from structured sales data from websites and geolocation data from mobile apps to unstructured data types from social media - and its real-time processing (Hosseini et al., 2017). However, data integration across channels has been identified as a major challenge on firms' path towards omnichannel business (Lewis et al., 2014; Neslin et al., 2006). Redesigning the existing IT infrastructure and implementing IT systems that integrate data across channels and enable holistic analysis of such data requires not only significant financial investments but also personnel with knowledge and expertise in this area (Lewis et al., 2014). In fact, a lack of customer analytics capabilities represents another key obstacle for many firms in their transition. Linking and analyzing data across channels can allow firms to make better predictions about consumer behavior and target them with more appealing offers. In the most basic case, it enables employees to access consistent information about consumers, orders, and products across all channels (von Briel, 2018). As the application of tracking technologies and data analytics is set to increase in priority 


\begin{tabular}{|c|c|c|c|}
\hline \multicolumn{3}{|c|}{ Multichannel Business } & Omnichannel Business \\
\hline \multirow{2}{*}{$\begin{array}{l}\text { Consumer } \\
\text { Viewpoint }\end{array}$} & - No transition between channels & Channel Transitions & $\begin{array}{l}\text { - Seamless transition between channels within the } \\
\text { same transaction }\end{array}$ \\
\hline & $\begin{array}{l}\text { - Inconsistent customer experience across } \\
\text { channels (e.g., in terms of products / services, } \\
\text { prices, promotions) }\end{array}$ & Customer Experience & $\begin{array}{l}\text { - Consistent customer experience across channels } \\
\text { (e.g., in terms of products / services, prices, } \\
\text { promotions) }\end{array}$ \\
\hline \multirow{4}{*}{$\begin{array}{l}\text { Firm } \\
\text { Viewpoint }\end{array}$} & $\begin{array}{l}\text { - Separated IT systems for each channel } \\
\text { - Separated databases for customer, pricing and } \\
\text { inventory data }\end{array}$ & Information Systems & $\begin{array}{l}\text { - Integrated IT systems across channels } \\
\text { - Central database for customer, pricing and } \\
\text { inventory data }\end{array}$ \\
\hline & $\begin{array}{l}\text { - Independent, siloed management of channels } \\
\text { - No knowledge sharing across channels }\end{array}$ & Channel Management & $\begin{array}{l}\text { - Coordinated and integrated management of } \\
\text { channels } \\
\text { - Knowledge sharing across channels }\end{array}$ \\
\hline & $\begin{array}{l}\text { - Directed towards channel competition } \\
\text { - Channels are optimized separately with each } \\
\text { channel pursuing individual goals }\end{array}$ & Incentive Schemes & $\begin{array}{l}\text { - Directed towards minimizing channel } \\
\text { competition and maximizing channel synergies }\end{array}$ \\
\hline & - Fragmented & Logistics & - Integrated across channels \\
\hline & \multicolumn{3}{|c|}{$\begin{array}{l}\text { The transition to omnichannel is characterized by technological, organizational, or market changes } \\
\text { and will at the same time afford changes to technologies, organizations and markets* }\end{array}$} \\
\hline
\end{tabular}

*Note that the characteristics multichannel and omnichannel business depicted here describe their ideal archetypes and manifold intermediate configurations are possible (and will occur during a transition process from multichannel to omnichannel).

Fig. 2 Characteristics of multichannel and omnichannel business

among businesses, data integration reinforces the need for firms to address ethical, legal, and privacy issues as part of their omnichannel strategy (Bradlow et al., 2017).

Second, omnichannel business requires an integrated logistics infrastructure that can effectively accommodate each channel. In many cases, this involves the redesign of existing distribution systems (Lewis et al., 2014) and the implementation of technologies facilitating real-time inventory management across channels (von Briel, 2018). Such investments are considered a key issue in channel integration (Piotrowicz \& Cuthbertson, 2014), and researchers have suggested pathways of transitioning from multichannel to integrated omnichannel fulfilment (Hübner et al., 2016c).
Third, successfully embracing omnichannel business requires developing and nurturing new organizational practices that foster intensified cross-channel communication and collaboration (von Briel, 2018). This necessitates a corporate culture that breaks up the often-prevailing silo mentality and promotes knowledge sharing across channels (Piotrowicz \& Cuthbertson, 2014). Achieving this goal often entails organizational restructuring, adding cross-channel performance metrics to incentive schemes, and hiring and training employees-from store to head office staff-with the necessary skills to manage multiple channels (Cao, 2014; Hansen \& Sia, 2015; Lewis et al., 2014; von Briel, 2018).

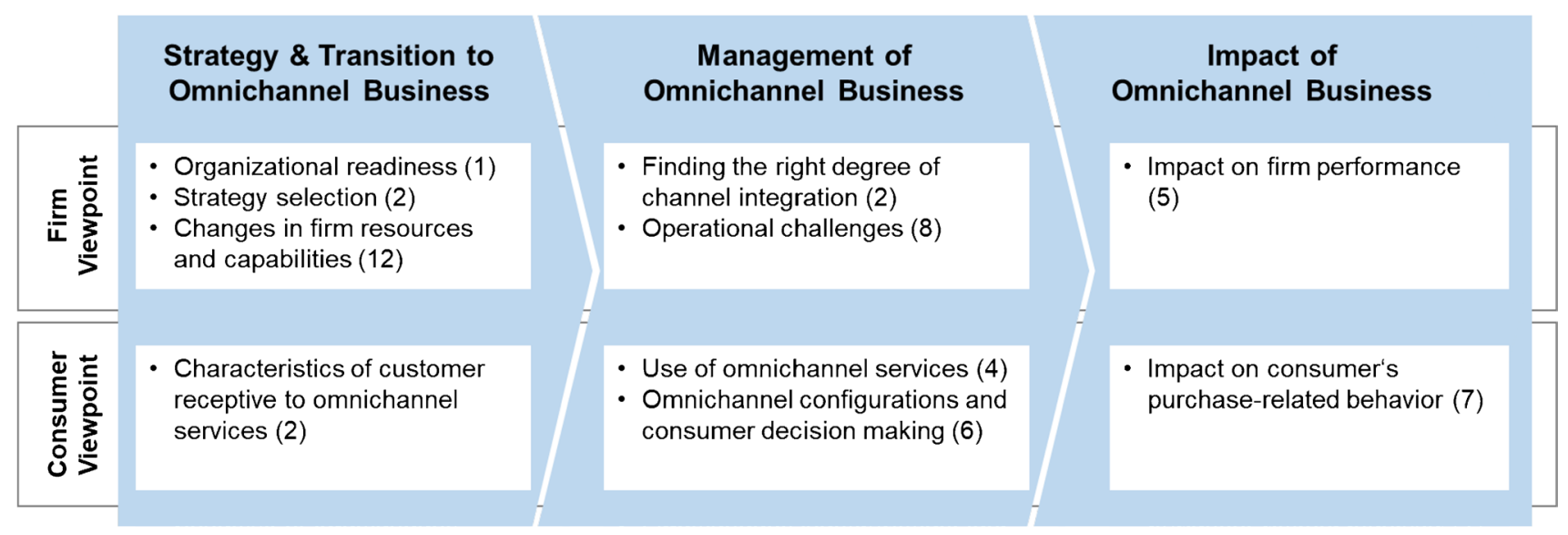

Fig. 3 Synthesis of prior research on omnichannel business (including number of papers in brackets) 
Taking a consumer focus, prior research has identified consumer segments that use multiple channels in their customer journey and are therefore particularly relevant for omnichannel businesses. Based on their channel use in the customer journey, five different segments were identified: store-focused shoppers, pragmatic online shoppers, extensive online shoppers, multiple touchpoint shoppers, and online-to-offline shoppers (Herhausen et al., 2019). In particular, multiple touchpoint shoppers and online-to-offline shoppers provide an attractive option for omnichannel businesses as they already use digital and physical channels and would appreciate a seamless customer journey. Similarly, omnichannel retailers might target younger double-income households with higher levels of education and income, as they seem the most receptive to adopting retailers' newer channels (Jindal et al., 2021).

\section{Research theme 2: Management of omnichannel business}

Integrating digital and physical channels can lead to synergies (e.g., resource sharing, cross-channel advertising), but also tensions (e.g., increased process complexity, internal conflicts) (Wiener et al., 2018). Therefore, it is essential for firms to find the right balance between channel integration and separation (Wiener et al., 2018) and to carefully manage the complex interplay between digital and physical channels. There is no one-size-fits-all approach to implementing and running an omnichannel business. Instead, contextual factors (e.g., industry) influence the extent to which firms can exploit cross-channel synergies (Wiener et al., 2018). Moreover, firms must take consumers' expectations into consideration, as a misalignment between those expectations and the organization's perception and implementation of channel integration can lead to negative customer experiences (Banerjee, 2014).

Managing an omnichannel business in an efficient manner has been a key concern for practice and research. Operational issues include the management of distribution systems, resource allocation, and customer journeys. Flexible and efficient distribution systems are a prerequisite for the provision of omnichannel services like store delivery, home delivery, and store pickup. Firms must orchestrate various dispatching locations and enable the shipment to various destination points. To support firms in efficiently managing their distribution systems, Hübner et al. (2016a) develop archetypes of omnichannel distribution concepts, while Hübner et al. (2016b) suggest a framework for last-mile order fulfilment and analyze the pros and cons of various design concepts in omnichannel retailing in the grocery industry. Moreover, focusing on specific omnichannel services such as click-and-collect or store return of online orders, scholars have developed decision models to help managers examine the cost and value of providing such services in different ways (He et al., 2020; Mahar \& Wright, 2017). For example, managers should resolve operational issues such as determining which stores should handle pickups and returns (Mahar \& Wright, 2017). Digging deeper into resource allocation issues, algorithms have been developed that enable firms to determine the number and allocation of service agents within a service center across channels (Ilk et al., 2018).

Another important management practice for omnichannel businesses is steering consumers towards those channels that firms consider preferable. This can be achieved by making use of marketing spillovers in which marketing efforts in one channel can be used to influence shopping outcomes in other channels (Shankar \& Kushwaha, 2020). Similarly, the configuration of fulfilment options (i.e., by means of inventory availability information and delivery and return options) can steer consumers into the channel that favors logistics efficiency or one the retailer wants to popularize (Wollenburg et al., 2018). Lastly, online-to-offline targeting using incentives can be an alternative approach for inducing consumers to buy online (Luo et al., 2020).

Adopting a consumer viewpoint, prior research shows that channel integration quality is a key determinant for consumers' use of omnichannel services (Shen et al., 2018). Channel integration quality encompasses two dimensions: interaction quality (i.e., process and content consistency) and channel-service configuration quality (Sousa \& Voss, 2006). Moreover, information integration across channels positively affects consumers' perceived usefulness and benefits (Yang et al., 2020). Beyond channel integration, Shi et al. (2020) conceptualize omnichannel customer experience as a five-dimensional concept (i.e., integration, consistency, connectivity, flexibility, and personalization) and examine its impact on consumers' intention to use omnichannel services.

Further consumer-focused studies reveal how distinct configurations of omnichannel services affect consumers' channel evaluations and decisions. Trenz et al. (2020) demonstrate how consumers' evaluations of omnichannel integration across transaction- and post-transaction phases impact their convenience and/or risk evaluations and finally their channel choice. Their study also uncovers the extent to which omnichannel configurations (e.g., immediate pick up in store, returns in store) can outperform technologically optimized multichannel services (i.e., same-day delivery). The positive effects of channel integration in the transaction phase (i.e., offering in-store pickup after an online purchase) on channel choice can be attributed to providing real-time information about inventory availability and reducing the hassle cost of shopping (Gao \& Su, 2017). Interestingly, the factors influencing consumers' choice of omnichannel services (e.g., home delivery of online orders, picking up online orders in store) differ between physical-first (i.e., 
Walmart) and digital-first retailers (i.e., Amazon) (Jindal et al., 2021). Turning to post-transaction services, MiquelRomero et al. (2020) focus on channel choice for post- purchase complaints. In one of the few studies investigating digital offerings in physical stores, Barann et al. (2020) uncover the factors influencing consumers' intentions to use them. Lastly, Gu and Tayi (2017) analyze consumers' behavior when confronted with different product placement strategies in the physical versus the digital store. The authors suggest that the retailer offer a higher-quality product or a higherdemand product exclusively through the digital channel to induce pseudo-showrooming behavior (Gu \& Tayi, 2017).

\section{Research theme 3: Impact of omnichannel business}

While the positive effects of omnichannel business on firm performance are often postulated, empirical studies on this relationship are scarce. Prior research suggests benefits to firms, including increased sales growth (Cao \& $\mathrm{Li}, 2015)$ and enhanced operational efficiency (Oh et al., 2012). Firms that better integrate their different channels can improve consumers' trust, increase their loyalty, boost conversion rates, and create greater opportunities to cross-sell (Cao \& $\mathrm{Li}, 2015)$. Separating the impact of omnichannel on digital and physical channels, Gallino and Moreno (2014) found that the deployment of a service to buy online and pick up in store from offline-first retailers decreases the firm's online sales, but at the same time leads to higher store traffic and thus higher store sales, ultimately resulting in a net increase. However, such a service might not always be beneficial to the retailer, but depends on the unit operating cost, consumer hassle cost, and cross-selling profit (Kong et al., 2020). Reversely, online-first retailers expanding towards omnichannel business by opening physical showrooms could benefit from increased sales as well as improved operational efficiency by increasing conversion and decreasing returns (Bell et al., 2018).

From a consumer viewpoint, channel integration in omnichannel business can yield a number of cognitive and behavioral outcomes. Positive service experience (Kumar et al., 2019), purchase intention (e.g., Herhausen et al., 2015), positive word-of-mouth (Lee et al., 2019), and retention (e.g., Bendoly et al., 2005; Li et al., 2018) are the most common outcomes identified in prior research. Integrating access to and knowledge about the physical channel into a digital channel by, for instance, providing a store locator or store assortment availability information via the digital store enhances consumer search intention, purchase intention, and willingness to pay (Herhausen et al., 2015). The quality of channel integration has a positive effect on consumers' cross-buying intentions (i.e., purchasing additional products from the same firm), perceived value (Hossain et al., 2020), and customer engagement (Lee et al., 2019), which thereby leads to positive word-of-mouth and repurchase intention.

\section{Avenues for future research}

Prior studies have led to significant progress in understanding particular phenomena that either pertain to the firm or the consumer viewpoint on omnichannel business. Building on those insights, we recommend that future research on omnichannel business embrace the complexity of omnichannel endeavors in its entirety, rather than focusing on either a firm-centric or a consumer-centric viewpoint. In fact, the strong interplay between firms' omnichannel strategies and consumers' omnichannel activities makes careful consideration of both viewpoints inevitable for advancing theory and practice. At the same time, future research should embrace the perspectives through which the unique nature of omnichannel business can be observed and studied best to derive strong contextualized contributions in this field, namely technology, organization, and market.

From a technological perspective, omnichannel businesses are confronted with continuous technological innovations such as cross-channel behavioral tracking, sensors, prediction tools based on artificial intelligence (AI), and smart assistant technologies while at the same time also constituting a driver for the development of new technologies such as retail VR environments. From an organizational perspective, omnichannel business continues to challenge the existing business models, required capabilities, promising firm cultures, and established success measurement and incentive models. At the same time, the proliferation of omnichannel business enables the facilitation of new cross-firm collaborations, integrated processes, and potentially new organizational forms. From a market perspective, changing requirements and a far more complex and scattered competitive landscape demand a deeper understanding of when and how omnichannel services are useful while at the same time disrupting the existing market structures and roles of firms, consumers, and partners. In the following table, we view the three themes discovered in prior research through the perspectives technology, organization, and market and discuss research opportunities that arise from this framework. Table 1 presents exemplary research questions across themes and perspectives.

\section{Perspectives on strategy and transition to omnichannel business}

Adopting a technology perspective, future research should investigate emerging technologies and channels and support omnichannel businesses in deciding which channels to offer and how to integrate them into the existing channel 


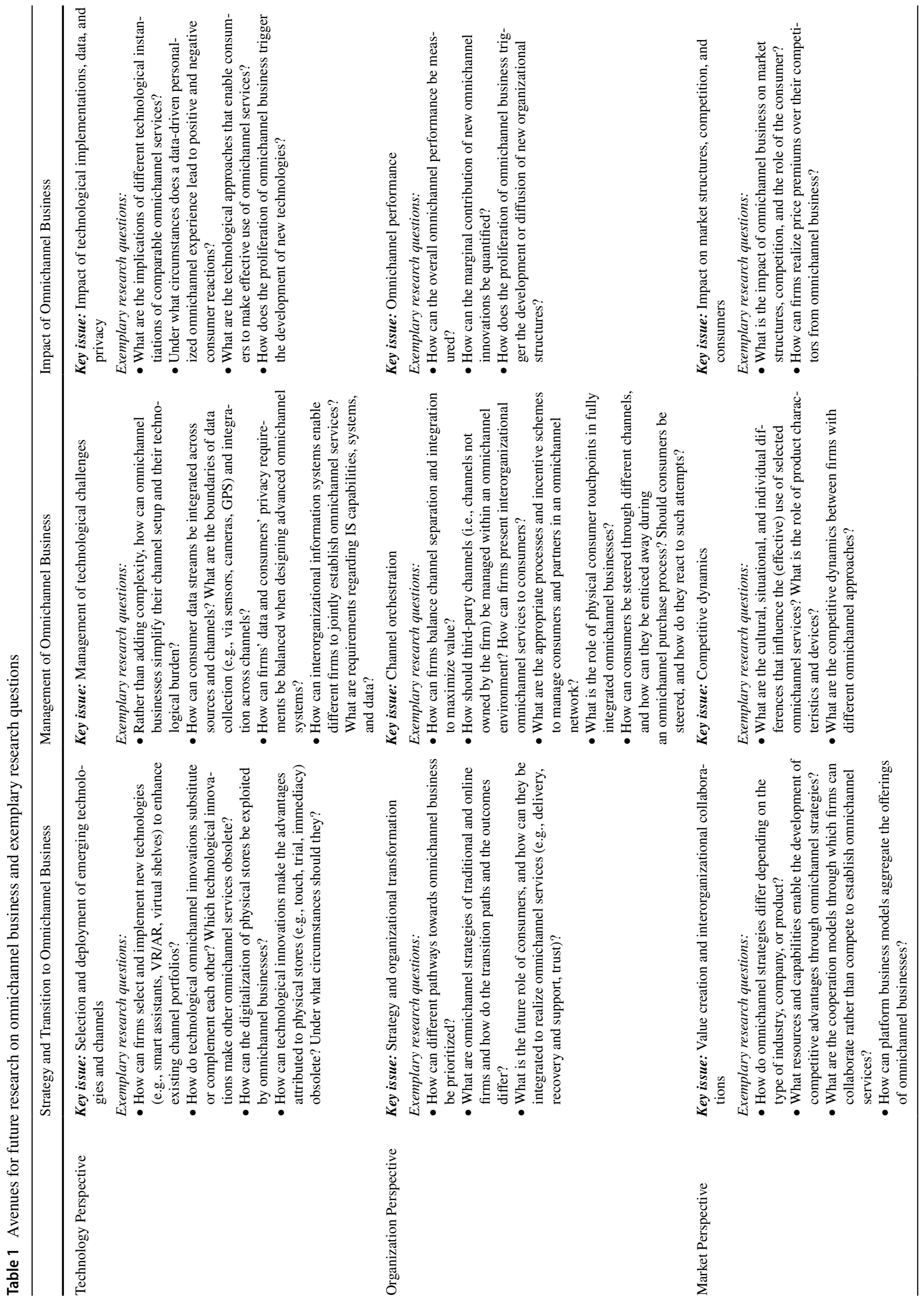


portfolio. Prior research on omnichannel business has primarily focused on the integration of physical stores and digital channels such as online and mobile stores. Digital channels like social media (Piotrowicz \& Cuthbertson, 2014) as well as innovative in-store technologies (Barann et al., 2020) have received little attention in omnichannel research. At the same time, new technologies that will transform the way firms and consumers interact already appear on the horizon, requiring firms to decide whether and how to integrate them effectively in their channel portfolio. For example, voice assistants are becoming increasingly relevant as purchase channels, and the Internet-of-Things will bring a vast number of channels, through which consumers will begin to interact with firms (von Briel, 2018).

From an organizational perspective, we require a better understanding of how omnichannel businesses can (and must) break up established boundaries within and across firms to facilitate the implementation of a unique omnichannel strategy. Scholars have already addressed important issues related to firms' transition to omnichannel business (e.g., Hansen \& Sia, 2015; Hosseini et al., 2018; Luo et al., 2016). Despite these valuable efforts, there are still many unanswered questions regarding the organizational transformation to become an omnichannel business. Prior research has shown that there is no one-size-fits-all approach to implementing an omnichannel strategy. Therefore, building on extant knowledge, it would be worthwhile to study how alternative pathways towards omnichannel business can be compared and weighed against each other. Moreover, given the strong focus of prior research on omnichannel strategies and pathways of traditional offline-first companies, further research should contrast those to online firms, thereby expanding initial research efforts (Bell et al., 2018; Jindal et al., 2021).

Future research on omnichannel business should also advance from the primary focus on individual firms towards a broader market perspective. Prior research suggests that omnichannel strategies differ depending on contextual factors (Wiener et al., 2018). Thus, we encourage scholars to go beyond the retail industry, which has been in the focus so far, and investigate omnichannel strategies in other industries such as the financial industry (Lehrer et al., 2018) and in relation to different types of products and services. To date, we know relatively little about how contextual factors such as industry or product types influence firms' omnichannel strategies and the implementation thereof. It is unclear why and how firms from industries other than retailing transition toward omnichannel business and how transformation challenges and market outcomes differ from the retail context.

Previous research on omnichannel business has focused primarily on individual firms and omnichannel business has mostly been presented as a strategy of traditional offline-first companies against the increasing pressure by online-first companies. However, in practice, we observe increasing collaboration between traditional offline and online firms to provide omnichannel services to consumers. For example, Amazon is increasingly cooperating with traditional retailers that offer pickup stations for online orders in their stores (Perez, 2019). Therefore, we encourage future research to go beyond a single-firm view and investigate interorganizational collaborations. To better understand the setup and success factors of such collaborations, it is useful to examine issues related to the required information systems, data, and processes. Moreover, investigating the appropriate governance structure for such collaborations and the distribution of power between omnichannel companies could be worthwhile.

Lastly, omnichannel so far has been frequently described as an opportunity for retailers to differentiate or to use their expensive infrastructure to realize superior customer experiences. However, their standardization and integration also give rise to entirely new models that have already disrupted other industries such as mobility or hospitality. The German fashion retailer Zalando, for instance, is testing platform integration approaches by connecting its inventory to hitherto independent local stores. By facilitating inter-firm inventory sharing, platform firms might be able to realize decentralized omnichannel services without owning products or infrastructure themselves (Zalando, 2020) and compete against existing omnichannel businesses without having to handle personnel, inventory, or other major costs or investments that omnichannel businesses currently bear.

\section{Perspectives on management of omnichannel business}

Omnichannel businesses have multiple technologies to choose from in order to expand their channel portfolio, and new technologies are continuously emerging. However, simply adding channels will further increase the operational complexity. Thus, research taking a technology perspective could propose ways to simplify firms channel setup and their technological burden.

From an organizational perspective, prior research has highlighted that channel integration can lead to synergies, but also tensions (Wiener et al., 2018). Therefore, research supporting firms in finding the right balance between channel separation and integration and to exploit cross-channel synergies is warranted. Moreover, the blurring boundaries between digital and physical channels in fully integrated omnichannel businesses give rise to research opportunities regarding the changing role of the physical consumer touchpoints. Promising research opportunities also arise from the changing role of consumers in omnichannel business and how this affects organizations' customer relationship management. Prior research has considered consumers as 
users of omnichannel services. However, consumers could be more integrated into the value creation process by taking over parts of the fulfilment or service activities (Zebra Technologies, 2018). This expands the traditional role of the consumer to include activities of the service provider, typically referred to as the prosumer role. Thus, we raise questions of what the future role of consumers will be and what such new work arrangements could look like. Research might investigate how consumers can and the extent to which they are willing to be integrated into the value creation process and what the appropriate processes and incentive schemes might be.

From a market perspective, we lack an understanding of how omnichannel businesses might (be able to) compete, which approaches are effective, and how new incumbents might disrupt the prospects of omnichannel businesses. Prior research has mostly investigated the competition between traditional, online, and multichannel businesses and has recently begun to compare their firm performance as well as consumer behavior by introducing omnichannel businesses into the picture (Trenz et al., 2020). As omnichannel businesses become more common, the focus of these investigations must shift towards competition between omnichannel businesses and consumers' decisions between a variety of omnichannel businesses with different foci and organizational setups and technologies in place. In this sense, it will become even more important to create sticky omnichannel experiences in which customers move fluently across channels, but not between firms.

\section{Perspectives on impact of omnichannel business}

From a technology perspective, we require a better understanding of the design and the peculiarities of different technological implementations. Most of the previous research into omnichannel business has categorized channels as digital or physical, regardless of their specific technological realization. Similarly, omnichannel services were addressed on a service rather than a technological level. Instead of dealing with the presence or absence of channels and services, omnichannel research should delve deeper into the technological characteristics and their impact on firms and consumers.

Another promising research area addresses issues related to the increasing data collection and use among omnichannel businesses. Beyond channel integration, omnichannel businesses aim to provide consumers with a personalized customer experience across and within each channel (Piotrowicz \& Cuthbertson, 2014; von Briel, 2018), based on crosschannel data. Personalization involves communication and services tailored to the individual consumer's preferences and situational context to maximize immediate and future business results (Shi et al., 2020). However, media's growing attention to firms' personalization practices raises consumers' awareness of how firms handle their personal information. Although consumers have come to expect relevant, personalized, and real-time (e.g., location-based) treatment from firms, they have increasing concerns about privacy and data security (Bradlow et al., 2017; Karwatzki et al., 2017a; Piotrowicz \& Cuthbertson, 2014). Since these concerns can trigger negative consumer reactions, future research should help firms strike the right balance between personalization and privacy (Karwatzki et al., 2017b).

From an organizational perspective, while prior research provides valuable insights into the impact of omnichannel business on firms and consumers (e.g., Cao \& Li, 2015; Kumar et al., 2019; Oh et al., 2012), many open questions remain that are worth investigating. To date, we lack a clear approach to measure overall omnichannel performance and to quantify the marginal contribution of new omnichannel innovations.

Research investigating omnichannel business from a market perspective could unearth the impact of omnichannel business on market structures, competition, and the role of the consumer. Another interesting issue is if and how firms can realize price premiums over their competitors from omnichannel business.

\section{Conclusion}

The emergence of omnichannel business has led to exciting opportunities for research and practice but at the same time presents unique challenges. To date, omnichannel research has been quite ambiguous in terms of its characteristics, scope, and boundaries as well as the state of research. This ambiguity creates unnecessary challenges for researchers and marketeers trying to navigate and advance research and practice in this area. This fundamentals article seeks to address this problem by providing a definition of omnichannel business that is grounded in its unique characteristics involving market, technology, and organizational perspectives and clearly distinguishes omnichannel from other terms such as multi- or cross-channel. We leverage this conceptual clarity to analyze and structure previous research on the topic and conclude with a framework that identifies opportunities for omnichannel business research. The pressing technological, organizational, and market issues should render omnichannel business an important field of research for information systems researchers. As such, this work is intended to provide researchers with orientation, inspiration, and a reference to position their own work. 


\section{Appendix}

\section{Literature search process}

The systematic literature review on omnichannel business by Mirsch et al. (2016) served as a starting point for our literature search. The majority of the 18 papers identified by Mirsch et al. (2016) are conceptual in nature, with very few empirical studies (e.g., Hansen \& Sia, 2015, Lewis et al., 2014; Piotrowicz \& Cuthbertson, 2014). We extracted those articles and included them in the present paper. To identify more recent empirical and prescriptive studies on omnichannel business, we conducted a scoping review in three stages.

First, applying the search terms "omnichannel" or "omni-channel" in the field title, keywords, and abstract, we searched the multidisciplinary databases EBSCOhost and Science Direct as well as the AIS Library. We searched for scholarly peer-reviewed journal publications as well as publications in the proceedings of the International Conference on Information Systems, as the leading conference in the IS field. Drawing on Mirsch et al. (2016), we considered articles published from 2016 until 2020.

Second, we excluded duplicates and articles not published in English. We then carefully reviewed the identified papers based on the title and abstract to decide which articles to review in full length. After excluding those articles that were not topic-related or merely conceptual, we determined 29 articles on omnichannel business to be relevant for this paper.

Third, conducting a backward search, we identified 11 additional articles. Some of these articles do not explicitly mention the term omnichannel; however, when analyzing their content, it became clear that they deal with integrated channels and are in line with our conceptualization of omnichannel business. Although the term omnichannel itself is not new, it only recently gained popularity. However, phenomena related to omnichannel business have been investigated before (Verhoef et al., 2015), although such research uses other terminology such as multichannel strategy (if well-integrated, e.g., Berman \& Thelen, 2004) and cross-channel integration (Cao \& Li, 2015). The terminological ambiguity made it necessary to extract those papers that either explicitly use the term or implicitly relate to the concept of omnichannel business. In line with our definition, we used the term omnichannel business whenever referring to such research independent of the terminology used in the paper.

Funding Open Access funding enabled and organized by Projekt DEAL.
Open Access This article is licensed under a Creative Commons Attribution 4.0 International License, which permits use, sharing, adaptation, distribution and reproduction in any medium or format, as long as you give appropriate credit to the original author(s) and the source, provide a link to the Creative Commons licence, and indicate if changes were made. The images or other third party material in this article are included in the article's Creative Commons licence, unless indicated otherwise in a credit line to the material. If material is not included in the article's Creative Commons licence and your intended use is not permitted by statutory regulation or exceeds the permitted use, you will need to obtain permission directly from the copyright holder. To view a copy of this licence, visit http://creativecommons.org/licenses/by/4.0/.

\section{References}

Amar, J., Jacobson, R., Kleinstein, B., \& Shi, A. (2020). Redefine the omnichannel approach: Focus on what truly matters. McKinsey. https://www.mckinsey.com/business-functions/operations/ourinsights/redefine-the-omnichannel-approach-focus-on-whattruly-matters. Accessed 14 November 2020.

Balasubramanian, S., Raghunathan, R., \& Mahajan, V. (2005). Consumers in a multichannel environment: Product utility, process utility, and channel choice. Journal of Interactive Marketing, 19(2), 12-30. https://doi.org/10.1002/dir.20032

Banerjee, M. (2014). Misalignment and its influence on integration quality in multichannel services. Journal of Service Research, 17(4), 460-474. https://doi.org/10.1177/1094670514539395

Barann, B., Betzing, J. H., Niemann, M., Hoffmeister, B., \& Becker, J. (2020). Exploring customers' likeliness to use e-service touchpoints in brick and mortar retail. Electronic Markets, 1-23. https://doi.org/10.1007/s12525-020-00445-0

Beck, N., \& Rygl, D. (2015). Categorization of multiple channel retailing in Multi-, Cross-, and Omni-Channel Retailing for retailers and retailing. Journal of Retailing and Consumer Services, 27, 170-178. https://doi.org/10.1016/j.jretconser.2015. 08.001

Bell, D. R., Gallino, S., \& Moreno, A. (2018). Offline showrooms in omnichannel retail: Demand and operational benefits. Management Science, 64(4), 1629-1651. https://doi.org/10.1287/mnsc. 2016.2684

Bendoly, E., Blocher, J. D., Bretthauer, K. M., Krishnan, S., \& Venkataramanan, M. A. (2005). Online/in-store integration and customer retention. Journal of Service Research, 7(4), 313-327. https://doi.org/10.1177/1094670504273964

Berman, B., \& Thelen, S. (2004). A guide to developing and managing a well-integrated multi-channel retail strategy. International Journal of Retail \& Distribution Management, 32(3), 147-156. https://doi.org/10.1108/09590550410524939

Bradlow, E. T., Gangwar, M., Kopalle, P., \& Voleti, S. (2017). The role of big data and predictive analytics in retailing. Journal of Retailing, 93(1), 79-95. https://doi.org/10.1016/j.jretai.2016. 12.004

Brynjolfsson, E., Hu, Y. J., \& Rahman, M. S. (2013). Competing in the age of omnichannel retailing. MIT Sloan Management Review, 54(4), 23-29.

Cao, L. (2014). Business model transformation in moving to a crosschannel retail strategy: A case study. International Journal of Electronic Commerce, 18(4), 69-96. https://doi.org/10.2753/ JEC1086-4415180403

Cao, L., \& Li, L. (2015). The impact of cross-channel integration on retailers' sales growth. Journal of Retailing, 91(2), 198-216. https://doi.org/10.1016/j.jretai.2014.12.005 
Chen, Y., Cheung, C. M. K., \& Tan, C.-W. (2018). Omnichannel business research: Opportunities and challenges. Decision Support Systems, 109, 1-4. https://doi.org/10.1016/j.dss.2018.03.007

Euromonitor International (2018). Best practices for omnichannel retailing. https://www.euromonitor.com/best-practices-foromnichannel-retailing/report. Accessed 18 August 2021.

Euromonitor International (2021). Global trends and corporate strategies in omnichannel. https://www.euromonitor.com/ globaltrends-and-corporate-strategies-in-omnichannel/report. Accessed 18 August 2021.

Forrester (2020). The omnichannel maturity assessment. https:// www.forrester.com/report/The+Omnichannel+Maturity+Asses sment/RES131141. Accessed 19 August 2021.

Gallino, S., \& Moreno, A. (2014). Integration of online and offline channels in retail: The impact of sharing reliable inventory availability information. Management Science, 60(6), 14341451. https://doi.org/10.1287/mnsc.2014.1951

Gao, F., \& Su, X. (2017). Omnichannel retail operations with buyonline-and-pick-up-in-store. Management Science, 63(8), 24782492. https://doi.org/10.1287/mnsc.2016.2473

Grewal, D., Roggeveen, A. L., \& Nordfält, J. (2017). The future of retailing. Journal of Retailing, 93(1), 1-6. https://doi.org/10. 1016/j.jretai.2016.12.008

Gu, Z., \& Tayi, G. (2017). Consumer pseudo-showrooming and omnichannel placement strategies. MIS Quarterly, 41(2), 583-606. https://doi.org/10.25300/MISQ/2017/41.2.11

Hansen, R., \& Sia, S. K. (2015). Hummel's digital transformation toward omnichannel retailing: Key lessons learned. MIS Quarterly Executive, 14(2), 51-66.

He, Y., Xu, Q., \& Wu, P. (2020). Omnichannel retail operations with refurbished consumer returns. International Journal of Production Research, 58(1), 271-290. https://doi.org/10.1080/00207543. 2019.1629672

Herhausen, D., Binder, J., Schoegel, M., \& Herrmann, A. (2015). Integrating bricks with clicks: Retailer-level and channel-level outcomes of online-offline channel integration. Journal of Retailing, 91(2), 309-325. https://doi.org/10.1016/j.jretai.2014.12.009

Herhausen, D., Kleinlercher, K., Verhoef, P. C., Emrich, O., \& Rudolph, T. (2019). Loyalty formation for different customer journey segments. Journal of Retailing, 95(3), 9-29. https://doi. org/10.1016/j.jretai.2019.05.001

Hosseini, S., Merz, M., Röglinger, M., \& Wenninger, A. (2018). Mindfully going omni-channel: An economic decision model for evaluating omni-channel strategies. Decision Support Systems, 109, 74-88. https://doi.org/10.1016/j.dss.2018.01.010

Hosseini, S., Röglinger, M., \& Schmied, F. (2017). Omni-Channel retail capabilities: An information systems perspective. Proceedings of the International Conference on Information Systems, Seoul, South Korea, December 2017

Hossain, T. M. T., Akter, S., Kattiyapornpong, U., \& Dwivedi, Y. (2020). Reconceptualizing integration quality dynamics for omnichannel marketing. Industrial Marketing Management, 87, 225-241. https://doi.org/10.1016/j.indmarman.2019.12.006

Hübner, A., Holzapfel, A., \& Kuhn, H. (2016a). Distribution systems in omni-channel retailing. Business Research, 9(2), 255-296. https:// doi.org/10.1007/s40685-016-0034-7

Hübner, A., Kuhn, H., \& Wollenburg, J. (2016b). Last mile fulfilment and distribution in omni-channel grocery retailing: A strategic planning framework. International Journal of Retail \& Distribution Management, 44(3), 228-247. https://doi.org/10.1108/ IJRDM-11-2014-0154

Hübner, A., Wollenburg, J., \& Holzapfel, A. (2016c). Retail logistics in the transition from multi-channel to omni- channel. International Journal of Physical Distribution \& Logistics Management, 46(6/7), 562-583. https://doi.org/10.1108/IJPDLM-08-2015-0179
Ilk, N., Brusco, M., \& Goes, P. (2018). Workforce management in omnichannel service centers with heterogeneous channel response urgencies. Decision Support Systems, 105, 13-23. https://doi.org/ 10.1016/j.dss.2017.10.008

Jindal, R. P., Gauri, D. K., Li, W., \& Ma, Y. (2021). Omnichannel battle between Amazon and Walmart: Is the focus on delivery the best strategy? Journal of Business Research, 122, 270-280. https://doi. org/10.1016/j.jbusres.2020.08.053

Karwatzki, S., Trenz, M., Tuunainen, V. K., \& Veit, D. (2017a). Adverse consequences of access to individuals' information: An analysis of perceptions and the scope of organisational influence. European Journal of Information Systems, 26(6), 688-715. https://doi.org/10.1057/s41303-017-0064-z

Karwatzki, S., Dytynko, O., Trenz, M., \& Veit, D. (2017b). Beyond the personalization-privacy paradox: Privacy valuation, transparency features, and service personalization. Journal of Management Information Systems, 34(2), 369-400. https://doi.org/10.1080/ 07421222.2017 .1334467

Kim, J. C., \& Chun, S. H. (2018). Cannibalization and competition effects on a manufacturer's retail channel strategies: Implications on an omni-channel business model. Decision Support Systems, 109, 5-14. https://doi.org/10.1016/j.dss.2018.01.007

Kong, R., Luo, L., Chen, L., \& Keblis, M. F. (2020). The effects of BOPS implementation under different pricing strategies in omnichannel retailing. Transportation Research Part e: Logistics and Transportation Review, 141, 102014. https://doi.org/10. 1016/j.tre.2020.102014

Kumar, V., Rajan, B., Gupta, S., \& Dalla Pozza, I. (2019). Customer engagement in service. Journal of the Academy of Marketing Science, 47(1), 138-160. https://doi.org/10.1007/s11747-017-0565-2

Lee, Z. W., Chan, T. K., Chong, A. Y. L., \& Thadani, D. R. (2019). Customer engagement through omnichannel retailing: The effects of channel integration quality. Industrial Marketing Management, 77, 90-101. https://doi.org/10.1016/j.indmarman.2018.12.004

Lehrer, C., Wieneke, A., Vom Brocke, J., Jung, R., \& Seidel, S. (2018). How big data analytics enables service innovation: Materiality, affordance, and the individualization of service. Journal of Management Information Systems, 35(2), 424-460. https://doi.org/10. 1080/07421222.2018.1451953

Lewis, J., Whysall, P., \& Foster, C. (2014). Drivers and technologyrelated obstacles in moving to multichannel retailing. International Journal of Electronic Commerce, 18(4), 43-68. https://doi. org/10.2753/JEC1086-4415180402

Li, Y., Liu, H., Lim, E. T., Goh, J. M., Yang, F., \& Lee, M. K. (2018). Customer's reaction to cross-channel integration in omnichannel retailing: The mediating roles of retailer uncertainty, identity attractiveness, and switching costs. Decision Support Systems, 109, 50-60. https://doi.org/10.1016/j.dss.2017.12.010

Lipsman, A. (2019). Global Ecommerce 2019 - Ecommerce continues strong gains amid global economic uncertainty. eMarketer. https://www.emarketer.com/content/global-ecommerce-2019. Accessed 14 November 2020.

Luo, J., Fan, M., \& Zhang, H. (2016). Information technology, crosschannel capabilities, and managerial actions: Evidence from the apparel industry. Journal of the Association for Information Systems, 17(5), 308-327. https://doi.org/10.17705/1jais.00429

Luo, X., Zhang, Y., Zeng, F., \& Qu, Z. (2020). Complementarity and cannibalization of offline-to-online targeting: A field experiment on omnichannel commerce. MIS Quarterly, 44(2), 957-982. https://doi.org/10.25300/MISQ/2020/15630

Mahar, S., \& Wright, P. D. (2017). In-store pickup and returns for a dual channel retailer. IEEE Transactions on Engineering Management, 64(4), 491-504. https://doi.org/10.1109/TEM.2017.26914 66 
Matthews, C. (2013). Best Buy's unlikely return from the dead. Time. http://business.time.com/2013/07/15/best-buys-unlikely-returnfrom-the-dead/. Accessed 5. November 2020.

Miquel-Romero, M. J., Frasquet, M., \& Molla-Descals, A. (2020). The role of the store in managing postpurchase complaints for omnichannel shoppers. Journal of Business Research, 109, 288296. https://doi.org/10.1016/j.jbusres.2019.09.057

Mirsch, T., Lehrer, C., \& Jung, R. (2016). Channel integration towards omnichannel management: A literature review. Proceedings of the 20th Pacific Asia Conference on Information Systems (PACIS), Chiayi, Taiwan.

Neslin, S. A., Grewal, D., Leghorn, R., Shankar, V., Teerling, M. L., Thomas, J. S., \& Verhoef, P. C. (2006). Challenges and opportunities in multichannel customer management. Journal of Service Research, 9(2), 95-112. https://doi.org/10.1177/1094670506 293559

Nüesch, R., Alt, R., \& Puschmann, T. (2015). Hybrid customer interaction. Business \& Information Systems Engineering, 57(1), 73-78. https://doi.org/10.1007/s12599-014-0366-9

Oh, L. B., Teo, H. H., \& Sambamurthy, V. (2012). The effects of retail channel integration through the use of information technologies on firm performance. Journal of Operations Management, 30(5), 368-381. https://doi.org/10.1016/j.jom.2012.03.001

Paré, G., Trudel, M.-C., Jaana, M., \& Kitsiou, S. (2015). Synthesizing information systems knowledge: A typology of literature reviews. Information \& Management, 52(2), 183-199. https://doi.org/10. 1016/j.im.2014.08.008

Pauwels, K., Leeflang, P. S., Teerling, M. L., \& Huizingh, K. E. (2011). Does online information drive offline revenues?: Only for specific products and consumer segments! Journal of Retailing, 87(1), 1-17. https://doi.org/10.1016/j.jretai.2010.10.001

Perez, S. (2019). Amazon expands its in-store pickup service, counter, to thousands more stores. TechCrunch. https://techcrunch.com/ 2019/10/23/amazon-expands-its-in-store-pickup-service-counterto-thousands-more-stores/. Accessed 10 November 2020.

Piotrowicz, W., \& Cuthbertson, R. (2014). Introduction to the special issue information technology in retail: Toward omnichannel retailing. International Journal of Electronic Commerce, 18(4), 5-16. https://doi.org/10.2753/JEC1086-4415180400

Rigby, D. (2011). The future of shopping. Harvard Business Review, $89(12), 65-76$

Shankar, V., \& Kushwaha, T. (2020). Omnichannel marketing: Are cross-channel effects symmetric? International Journal of Research in Marketing, 38(2), 290-310. https://doi.org/10.1016/j. ijresmar.2020.09.001

Shen, X. L., Li, Y. J., Sun, Y., \& Wang, N. (2018). Channel integration quality, perceived fluency and omnichannel service usage: The moderating roles of internal and external usage experience. Decision Support Systems, 109, 61-73. https://doi.org/10.1016/j. dss.2018.01.006

Shi, S., Wang, Y., Chen, X., \& Zhang, Q. (2020). Conceptualization of omnichannel customer experience and its impact on shopping intention: A mixed-method approach. International Journal of Information Management, 50, 325-336. https://doi.org/10.1016/j. ijinfomgt.2019.09.001
Sousa, R., \& Voss, C. A. (2006). Service quality in multichannel services employing virtual channels. Journal of Service Research, 8(4), 356-371. https://doi.org/10.1177/1094670506286324

Trenz, M., Veit, D., \& Tan, C.-W. (2020). Disentangling the impact of omnichannel integration on consumer behavior in integrated sales channels. MIS Quarterly, 44(3), 1207-1258. https://doi.org/10. 25300/MISQ/2020/14121

Väänänen, H. (2020). The future of retail isn't physical vs online, it's omnichannel. Forbes. https://www.forbes.com/sites/heikkivaan anen/2020/07/01/the-future-of-retail-isnt-physical-vs-online-itsomnichannel/. Accessed 3 October 2020.

Verhoef, P. C., Kannan, P. K., \& Inman, J. J. (2015). From multi-channel retailing to omni-channel retailing: Introduction to the special issue on multi-channel retailing. Journal of Retailing, 91(2), 174-181. https://doi.org/10.1016/j.jretai.2015.02.005

von Briel, F. (2018). The future of omnichannel retail: A four-stage Delphi study. Technological Forecasting and Social Change, 132, 217-229. https://doi.org/10.1016/j.techfore.2018.02.004

Wang, R. J. H., Malthouse, E. C., \& Krishnamurthi, L. (2015). On the go: How mobile shopping affects customer purchase behavior. Journal of Retailing, 91(2), 217-234. https://doi.org/10.1016/j. jretai.2015.01.002

Wiener, M., Hoßbach, N., \& Saunders, C. (2018). Omnichannel businesses in the publishing and retailing industries: Synergies and tensions between coexisting online and offline business models. Decision Support Systems, 109, 15-26. https://doi.org/10.1016/j. dss.2018.01.008

Wollenburg, J., Holzapfel, A., Hübner, A., \& Kuhn, H. (2018). Configuring retail fulfillment processes for omni- channel customer steering. International Journal of Electronic Commerce, 22(4), 540-575. https://doi.org/10.1080/10864415.2018.1485085

Wulf, J., Mettler, T., \& Brenner, W. (2017). Using a digital services capability model to assess readiness for the digital consumer. MIS Quarterly Executive, 16(3), 171-195.

Yang, Y., Gong, Y., Land, L. P. W., \& Chesney, T. (2020). Understanding the effects of physical experience and information integration on consumer use of online to offline commerce. International Journal of Information Management, 51. https://doi.org/10.1016/j. ijinfomgt.2019.102046

Yrjölä, M., Saarijärvi, H., \& Nummela, H. (2018). The value propositions of multi-, cross-, and omni-channel retailing. International Journal of Retail \& Distribution Management, 46(11/12), 11331152. https://doi.org/10.1108/IJRDM-08-2017-0167

Zebra Technologies (2018). Reinventing the supply chain: The future of fulfillment vision study. https://www.zebra.com/content/dam/ zebra_new_ia/en-us/solutions-verticals/vertical-solutions/retail/ vision-study/fulfillment-vision-study-report-en-us.pdf. Accessed 25 October 2020.

Zalando (2020). Building connections: Offline to online. https://corpo rate.zalando.com/en/innovation/building-connections-offlineonline. Accessed 5 November 2020.

Publisher's note Springer Nature remains neutral with regard to jurisdictional claims in published maps and institutional affiliations. 